\title{
BMJ Open Spatial inequalities of major lower limb amputation rates in Paraná state, Brazil
}

\author{
Rogério do Lago Franco (D) , ${ }^{1}$ Pedro Henrique lora, ${ }^{1}$ Amanda Carvalho Dutra, ${ }^{2}$ \\ Sérgio Quilici Belczak, ${ }^{3}$ João Vissoci, ${ }^{4}$ Catherine Staton, ${ }^{4}$ Luciano Andrade ${ }^{1}$
}

To cite: Franco RdL, lora PH, Dutra AC, et al. Spatial inequalities of major lower limb amputation rates in Paraná state, Brazil. BMJ Open 2020;10:e038980. doi:10.1136/ bmjopen-2020-038980

- Prepublication history for this paper is available online. To view these files, please visit the journal online (http://dx.doi. org/10.1136/bmjopen-2020038980).

Received 31 March 2020 Revised 30 0ctober 2020 Accepted 25 November 2020

Check for updates

(C) Author(s) (or their employer(s)) 2020. Re-use permitted under CC BY-NC. No commercial re-use. See rights and permissions. Published by BMJ.

${ }^{1}$ Medicine Department, Universidade Estadual de Maringa, Maringa, Brazil

${ }^{2}$ Centro de Ciencias da Saude, Universidade Estadual de Maringa, Maringa, Brazil

${ }^{3}$ Medicine Department, Centro Universitário São Camilo, Sao Paulo, Brazil

${ }^{4}$ Division of Emergency Medicine, Duke University, Durham, North Carolina, USA

Correspondence to

Dr Rogério do Lago Franco; rogeriolfranco@yahoo.com.br

\section{ABSTRACT}

Objective The aim of this observational cross-sectional study was to analyse the spatial distribution of major lower limb amputation (MLLA) rates and associate them to socioeconomic, demographic and public healthcare access-related variables in the State of Paraná, Brazil, from 2012 to 2017

Method Data on MLLA, revascularisation surgeries, diagnostic exams and healthcare coverage were obtained from the Brazilian Public Hospital Information System. Socioeconomic data were obtained from the Brazilian Institute of Geography and Statistics. Spatial autocorrelation of the MLLA rates was tested using Moran's I method. Multivariate spatial regression models using ordinary least squares regression (OLS) and geographically weighted regression (GWR) were used to identify the variables significantly correlated with MLLA. Results A total of 5270 MLLA were included in the analysis. Mean MLLA rates were $24.32( \pm 18.22) / 100$ 000 inhabitants, showing a positive global spatial autocorrelation (Moran's $\mathrm{l}=0.66 ; \mathrm{p}<0.001)$. Queen contiguity matrix demonstrates that MLLA rates ranged from 7.6 to 46.6/100 000 with five large clusters of high MLLA rates. OLS showed that four of the nine studied variables presented significant spatial correlation with MLLA rates. Colour Doppler ultrasound showed a negative association $(p<0.001)$, while revascularisation surgeries and illiteracy showed a positive correlation $(p<0.01)$. GWR presented the best model (adjusted $R^{2}=0.77$ ) showing that the predictors differentially affect the MLLA rates geographically.

Conclusion The high MLLA rates in some regions of the state are influenced by the high rate of illiteracy and low utilisation rate of colour Doppler, indicating a social problem and difficulty in accessing health. On the other hand, the high rates of revascularisation surgeries are related to higher MLLA rates, possibly due to delayed access to specialised hospitals. This indicates that attention must be given to population access to public healthcare in the State of Paraná in order to ensure proper and timely medical attention.

\section{INTRODUCTION}

The last few decades have been marked by important technological advances in the treatment of occlusive peripheral arterial disease (PAD). While early diagnosis and treatment can improve prognosis and avoid limb amputation, delayed care continues to
Strengths and limitations of this study

- It is the first research on major lower limb amputations rates and the spatial-area differences and socioeconomic disparities in Brazil.

- A large volume of information and variables on the diagnostic and surgical procedures performed by the public health system were analysed.

- Different multivariate regression models (ordinary least squares regression and geographically weighted regression) were used to find the one with the best fit.

- The limitations mainly concern the fact that our data were obtained from the Brazilian Healthcare System database (DATASUS), which may be subject to underreporting.

result in unnecessary amputations, even in developed countries. ${ }^{1-4}$

Risk factors associated with PAD such as diabetes mellitus, hypertension, dyslipidaemia, heart diseases and smoking have been extensively studied to define preventive measures against amputation. ${ }^{256}$ Nonetheless, these diseases may receive different forms of attention, depending on the structure where the patient lives. ${ }^{7}$ Health resources may not be evenly distributed, and the socioeconomic status of the population may vary from place to place. As a result, the ecological/spatial impact that these factors have on the treatment of PAD and lower limb amputation rates, as a health system performance concern, is still largely unknown. ${ }^{2}$

Geospatial analysis of chronic diseases has been used to study local versus global factors (geographically distributed within a given space, municipality vs a whole country) that influence the occurrence of certain diseases in different regions or geographical areas (such as municipalities or census tracts). ${ }^{8}$ In search of geographical patterns, previous authors have focused their efforts on regional (local) differences in lower limb amputation rates in their respective countries, correlating their findings with spatial-area-specific risk factors, preventive actions, and accessibility 
to healthcare services, in both quantitative and distance terms. ${ }^{8-12}$ In Brazil, regional disparities in the incidence of issues such as coronary disease and cancer have already been studied. ${ }^{1314}$ These studies have shown important geographical inequities in access to healthcare (availability of tests, treatments, surgical procedures and primary care) or social determinants (literacy, unemployment and Human Development Index) of care throughout Brazil. However, lower limb amputation rates, especially those conducted above the ankle (major), and the spatial-area differences and socioeconomic disparities have yet to be identified.

As such, the aim of this study was to analyse the spatial distribution of major lower limb amputation (MLLA) rates and correlate them to public healthcare accessrelated variables in the treatment of $\mathrm{PAD}$ in a population in the State of Paraná, Brazil.

\section{METHODS}

This observational cross-sectional ecological study based on secondary data was designed to analyse the number of MLLA performed by the National Unified Health System in the State of Paraná. Data were abstracted from January 2012 to December 2017.

This study did not require ethical approval and consent from each individual since the data used were secondary and were publicly available on the government databases (DATASUS). This study followed the Brazilian national guidelines for research with human subjects and is reported according to Strengthening the Reporting of Observational Studies in Epidemiology (STROBE) guidelines. ${ }^{15}$

\section{Area of study}

The State of Paraná is located in southern Brazil and has a population of 11.34 million inhabitants. Of those, $31 \%$ live in the metropolitan area of its capital city, Curitiba. The state is administratively composed of 399 municipalities, distributed in 10 independent administrative health regions (figure 1), and holds the fifth highest Human Development Index (HDI=0.749) among the 27 Brazilian states. $^{1617}$

\section{Data source}

Data on the number of MLLA, open and endovascular revascularisation procedures, diagnostic exams (colour Doppler ultrasound and arteriography), public primary healthcare coverage and private medical insurance coverage were compiled for each of the 399 municipalities from Brazilian Public Hospital Information System (DATASUS). ${ }^{18}$

Demographic and socioeconomic data such as number of inhabitants, illiteracy and income ratio per inhabitant per municipalities were obtained from the Brazilian Institute of Geography and Statistics. ${ }^{16}$ The State of Paraná cartographic data were obtained from the State of Paraná Institute of Land, Cartography and Geology. ${ }^{19}$

We included all MLLA procedures (DATASUS code 04.08.05.001-2) performed in patients 40 years old or older, listing the following ICD-10 diagnoses: A48, E10, E11, E12, I70, I73, I74, I77, I79 and R02. Procedures related to trauma and oncological diagnosis (ICD-10 chapters II, XIX and XX) were excluded from the analysis. ${ }^{18}$ To reduce extreme behaviour in cities with very small or very large populations, the MLLA rates per 100000 inhabitants, adjusted to age over 40 years old, were calculated for each of the 399 cities in the State of Paraná using the empirical Bayesian estimate with the queen contiguity matrix (GeoDa software, v.1.12.0).$^{20} 21$

Open surgical and endovascular revascularisation procedure data were collected for patients over 40 years old (DATASUS codes from 04.06.02.012-4 to 04.06.02.045-0 and from 04.06.04.002-8 to 04.06.04.028-1, respectively). Diagnostic exam data were collected for all patients over 15 years old (colour Doppler ultrasound code 02.05.01.004-0 and arteriography codes from 02.10.01.006-1 to 02.10.01.015-0). Rates were calculated per 100000 inhabitants. Public primary health coverage is presented as a percentage as well as private medical insurance coverage. ${ }^{18}$

\section{Patient and public involvement}

No patient involved.

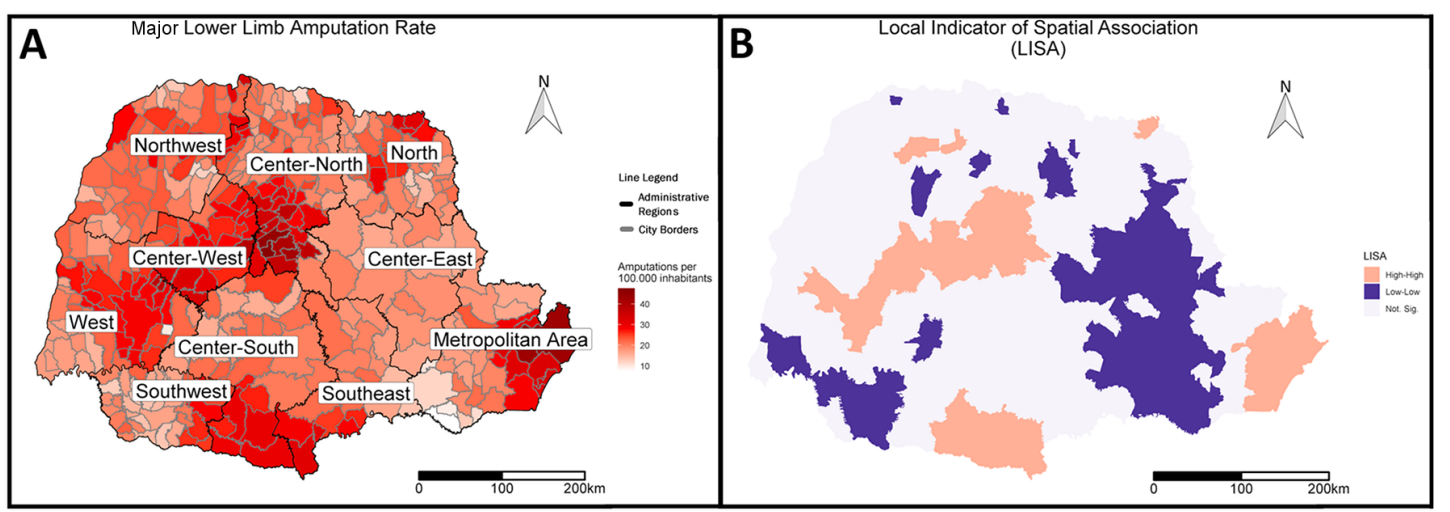

Figure 1 (A) Spatial distribution of major lower limb amputation (MLLA) rates between 2012 and 2017 in the State of Paraná. (B) Univariate local indicators of spatial autocorrelation clusters of MLLA rates. 


\section{Data analysis}

Spatial analysis

Exploratory spatial data analysis was performed with Moran's I index to determine global spatial autocorrelation and local indicators of spatial autocorrelation (LISA) to verify the influence of spatiality on MLLA rates using GeoDa software. ${ }^{21}$ Moran's I coefficient (univariate) and LISA coefficients were considered significant when $\mathrm{p}<0.05$.

Moran's I index ranges from -1 to +1 . Values higher or lower than the expected Moran's I value (E $(I)=-1 /(n-1))$ refer to positive or negative autocorrelation, respectively. A positive spatial autocorrelation indicates that a given area has similar pattern with the surrounding areas; for example, an area with high MLLA rates has similar neighbouring areas with high MLLA rates. A negative spatial autocorrelation indicates that a given area has an inverse association with the surrounding areas; for instance, an area with high MLLA rates has neighboring areas with low MLLA rates. The zero Moran's I value indicates the spatial independence hypothesis. ${ }^{20}$

However, Moran's I identifies only spatial association globally. To verify significant association patterns to each specific analysed area, LISA was used because it observes the existence of spatial groups (clusters) with high or low values, identifying the regions that most contribute to the existence of spatial autocorrelation. ${ }^{20}$

Spatial clusters were categorised according to the patterns and characteristics of adjacent municipalities. High-high spatial clusters are sets of municipalities with high MLLA rates surrounded by other municipalities also with high MLLA rates. On the other hand, low-low spatial clusters represent the municipalities with low MLLA rates surrounded by other municipalities with low MLLA rates.

\section{Spatial regression}

Because Global and Local Moran's I are univariate statistical analysis techniques, multivariate regression models with spatial dependence control were used to associate the dependent variable (MLLA rate) with nine public healthcare access-related independent variables (colour Doppler ultrasound rate, general and lower limb arteriography exam rates, open surgery rates, endovascular procedure rates, income ratio, illiteracy percentage, public primary healthcare coverage and private medical insurance coverage). The models used were ordinary least squares regression (OLS) and geographically weighted regression (GWR).

In the OLS analysis, all the nine variables associated with MLLA rates were included in the model to obtain the combination of variables that presented significant spatial correlation with MLLA rates with the most appropriate values of the Akaike information criterion (AIC) / Bayesian information and smaller multicollinearity. The coefficients of each predictor that were significant in the OLS model were then tested by the GWR model to identify the association of MLLA rates and the predictors in space evaluated. Model performance was evaluated using adjusted $\mathrm{R}^{2}$, AIC and Moran's I index residuals. ${ }^{22}$ Spatial data exploratory analysis was performed using GeoDa (V.1.12.0), QGIS (V.2.14) and Rstudio (V.1.1.463). ${ }^{21} 2324$

Choropleth maps were built with the data obtained showing the distribution of MLLA and the GWR spatial correlation analysis.

\section{RESULTS}

During the study period, 6936 MLLA were identified in the national records. Of those, 1666 (24\%) were performed in patients under 40 years old or due to traumatic or oncological reasons. As a result, a total of 5270 MLLA were included in the analysis. The mean age of patients was $67.8( \pm 11.97)$ years, of whom $63.62 \%$ were male. The number of diagnostic and surgical procedures performed during the studied period is presented in table 1.

Between 2012 and 2017, the mean MLLA rates in the State of Paraná were $24.32( \pm 18.22) / 100000$ inhabitants. Queen contiguity matrix demonstrated that MLLA rates ranged from 7.6 to $46.6 / 100000$. Approximately $25 \%$ of the municipalities in the State of Paraná presented MLLA rates ranging between 26.3 and 46.6/100 000 (figure 1A).

Table 1 Diagnostic and surgical procedures performed and sociodemographic and access-related variables analysed between 2012 and 2017 in the State of Paraná

\begin{tabular}{|c|c|c|c|c|c|}
\hline Variable & Total & Annual mean & Rate/100 000 & Mean \% & SD \\
\hline Open surgery & 6057 & 1009.50 & 13.86 & - & 10.40 \\
\hline Total arteriography & 7890 & 1315 & 11.66 & - & 15.78 \\
\hline Lower limb arteriography & 2272 & 378.66 & 3.40 & - & 4.68 \\
\hline Illiteracy & - & - & - & 10.2 & 3.92 \\
\hline Public primary healthcare coverage & - & - & - & 88.7 & 19.40 \\
\hline Private medical insurance coverage & - & - & - & 10.4 & 9.00 \\
\hline
\end{tabular}


Global Moran's I univariate analyses showed a positive spatial autocorrelation for MLLA rates $(\mathrm{I}=0.66, \mathrm{p}<0.001)$. Univariate LISA clusters for MLLA rates demonstrated five high-high clusters of municipalities with high MLLA rates surrounded by other municipalities with high MLLA rates, containing 62 municipalities $(15.5 \%)$. The largest high-high cluster of municipalities was concentrated in the central-west region of the state, extending from the west to the north regions. Other high-high clusters were located in the capital city of the state and in the surrounding metropolitan area and in parts of the centralsouth and south-east regions. Nine low-low clusters were observed, and the main one was located in parts of the north, central-east and south-east regions (figure 1B).

We used the OLS linear regression model to identify the factors with possible influences on AMI rates in different municipalities. Among the nine public healthcare accessrelated variables controlled by the multicollinearity tests, four presented significant spatial correlation with MLLA rates: colour Doppler ultrasound, open surgery, endovascular procedures and illiteracy rates. Colour Doppler ultrasound showed a significant negative correlation with MLLA rates, demonstrating that the less this exam was performed, the higher the MLLA rates in the municipalities $(p=0.00042)$. On the contrary, open surgery, endovascular procedures and illiteracy were positively correlated with MLLA, that is, the more these variables were present, the higher the MLLA rates in the municipalities. The GWR model was able to better explain the spatial correlation between MLLA rates and the predictors as demonstrated in table 2. The GWR model was able to explain $77 \%\left(\mathrm{R}^{2}=77\right)$ of events in space, and their residues did not demonstrate spatial autocorrelation (residual Moran's $\mathrm{I}=0132$ ) (table 2).

Figure 2 illustrates the spatial distribution of the coefficients of the association between MLLA rates and their predictors and their uncertainty obtained with the GWR model. MLLA rates were most negatively associated with colour Doppler ultrasound rate in the southern, northern, central and metropolitan regions (figure 2A).
MLLA rates were positively associated with open revascularisation surgery in the central, northwest, west, southern and metropolitan regions (figure 2B). MLLA rates were most positively associated with endovascular revascularisation procedures in the central-south, west, north and metropolitan regions (figure 2C). Finally, figure 2D demonstrates a positive association between LLA rates and illiteracy in the central-north, northwest, west and central-south regions.

\section{DISCUSSION}

To the best of our knowledge, this is the first analysis of its kind in Brazil. This study investigated the spatial autocorrelation of MLLA rates and public healthcare accessrelated variables in the treatment of $\mathrm{PAD}$. The results clearly demonstrated that MLLA rates were higher in some geographical regions in the State of Paraná than others, forming high-high clusters, where neighbouring municipalities tended to show similar rates. The findings also demonstrated a negative association between MLLA rates and colour Doppler ultrasound and a positive association between MLLA rates and open surgery, endovascular procedures and illiteracy.

Although the State of Paraná presents one of the highest HDI in Brazil, the average MLLA rates from the state $(24.32 / 100000$ inhabitants) were shown to be among the eight highest in the country, contradicting the expectation of a better medical structure and access. ${ }^{25}$ The fact that MLLA rates ranged from 7.6 to 46.6/100 000 suggests important disparities among the municipalities. The five high-high clusters identified indicate the areas where access to treatment of $\mathrm{PAD}$ in the public healthcare should receive more attention by health managers.

Among the socioeconomic variables included in the present study, only illiteracy was positively associated with MLLA rates, indicating that the lack of proper education can have a significant negative effect on access to public healthcare and in the adherence of patients to proposed treatments, in accordance with previous studies. ${ }^{8} 2627$

\begin{tabular}{|c|c|c|c|c|c|}
\hline \multirow[b]{2}{*}{ Variable } & \multicolumn{4}{|c|}{ OLS model (global model) } & \multirow{2}{*}{$\begin{array}{l}\text { GWR model (local } \\
\text { model) }\end{array}$} \\
\hline & Coefficient & SD & $\mathbf{t}$ & $P$ value & \\
\hline Constant & 1866 & 0.08747 & 21,33 & 0 & - \\
\hline Colour Doppler ultrasound & $-0,002$ & 0.00062 & -3.56 & 0.00042 & - \\
\hline Endovascular procedures & 0.097 & 0.03376 & 2.88 & 0.0042 & - \\
\hline Open surgery & 0.141 & 0.03052 & 4.62 & 0.00001 & - \\
\hline Illiteracy & 0.019 & 0.00767 & 2.42 & 0.01606 & - \\
\hline AlC & & 696.35 & & & 295.11 \\
\hline Adjusted $\mathrm{R}^{2}$ & & 0.14 & & & 0.77 \\
\hline Sum of residual squares & & 129.83 & & & 34.01 \\
\hline Moran's I (residual) & & 0.54 & & & 0.132 \\
\hline
\end{tabular}

GWR, geographically weighted regression; OLS, ordinary least squares regression. 


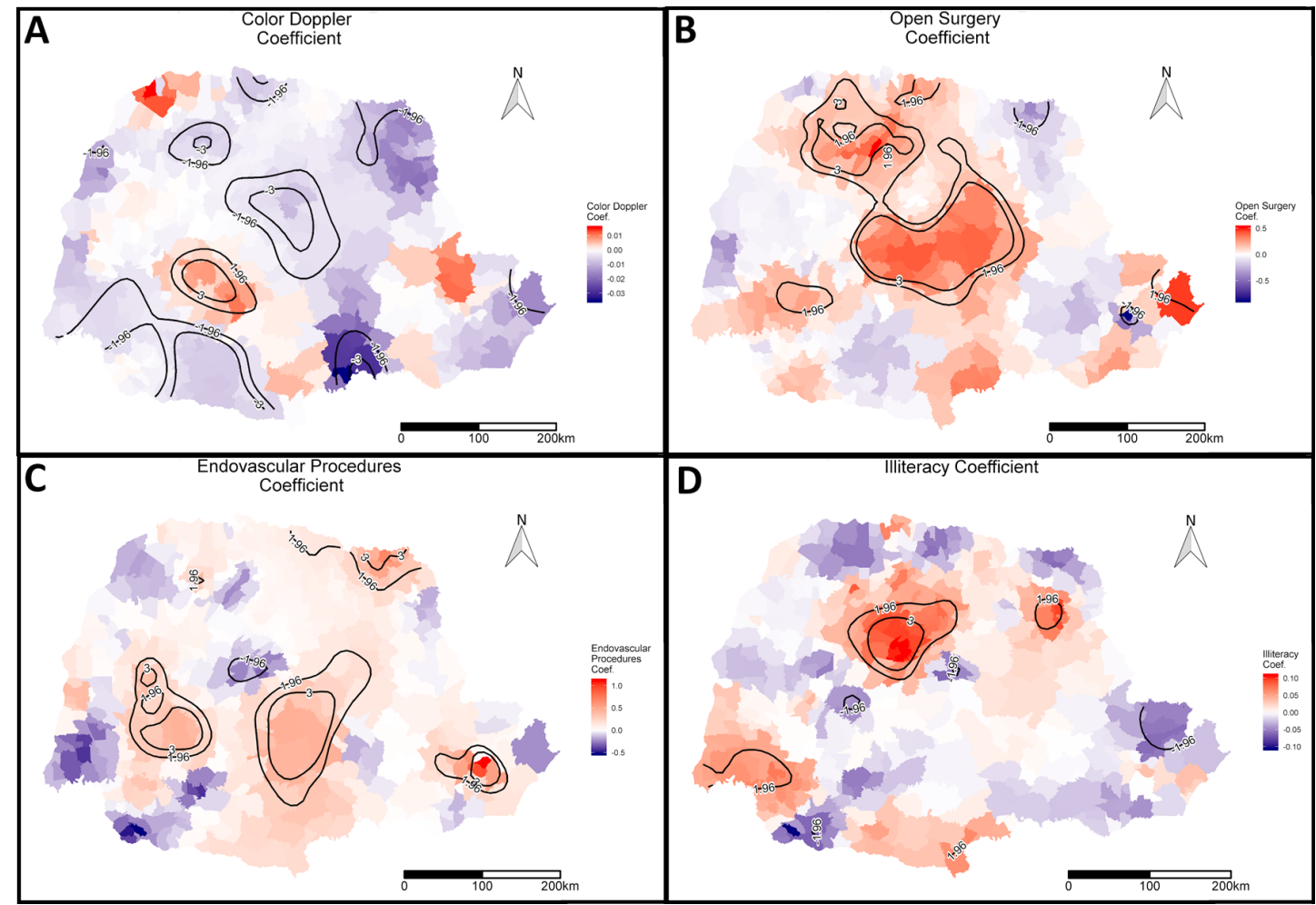

Figure 2 (A) Geographically weighted regression (GWR) analysis showing the negative correlation coefficients (blue) between major lower limb amputation (MLLA) rates and color Doppler ultrasound rates.(B) GWR analysis showing the positive correlation coefficients (red) between MLLA rates and open revascularisation surgery rates. (C) GWR analysis showing the positive correlation coefficients (red) between MLLA rates and endovascular revascularisation procedure rates. (D) GWR analysis showing the positive correlation coefficient (red) between MLLA and illiteracy.

Although income was not shown to be significant, the finding that illiterate people are more likely to undergo MLLA seems to indicate that more attention should be given to public primary healthcare coverage and attention in order to ensure the most vulnerable members of the population are properly served.

Colour Doppler ultrasound has become an important tool in the decision-making process for the treatment of patients with obstructive $\mathrm{PAD}$ in a manner comparable with arteriography. ${ }^{28}$ Colour Doppler ultrasound showed a significant negative spatial correlation with the MLLA, that is, areas where less exams were performed were also areas where higher MLLA rates were observed in the municipalities. This indicates that this type of exam does not seem to be readily available in many municipalities, hindering PAD early diagnosis and treatment and resulting in more MLLA.

On the other hand, open surgery and endovascular procedures showed a significant positive spatial association with the MLLA rates. While it cannot be said that open surgery and endovascular procedures are ineffective, from geographical standpoint, areas with higher procedure rates are also areas with high MLLA rates. A potential explanation to this result is patients could be arriving at specialist services at a very late stage of the disease, diminishing the effectiveness of limb salvage surgeries, leading to more amputations, as suggested in prior clinical studies. ${ }^{29}$ Moreover, the present analysis showed that arteriography and surgical procedures were collinear, that is, arteriography was frequently performed as part of surgical planning.

Prior literature on open surgery and endovascular interventions is controversial regarding their correlation with lower limb amputation rates. While some studies showed decreased lower limb amputation rates following these procedures ${ }^{29-32}$ some authors have shown that this expected benefit often does not occur at very advanced stages of the disease. ${ }^{30}$ Moreover, a recent study showed that patients initially treated with open surgery presented higher lower limb amputation rates than those treated with endovascular techniques. ${ }^{33}$ The authors concluded that the choice for open surgery was possibly being made for those patients with PAD at more advanced stages when prognosis is poorer. Although the correlation between MLLA rates and endovascular procedures was also significantly positive, it was $40 \%$ lower than the correlation with open surgeries, in agreement with a previous study that suggested that patients undergoing endovascular treatment will evolve with fewer MLLA rates. ${ }^{33}$

It has been previously suggested that developing countries should focus their efforts on primary intervention (prevention) in order to reduce the occurrence of lower limb amputation ${ }^{34}$; in a second step, investment should be made in early diagnosis and clinical treatment; and finally, accessibility to surgical/interventional treatments should be improved. ${ }^{34}$ The findings of this study suggest 
that the State of Paraná is presently at the second stage, in which more investment should be made in early diagnosis and clinical treatment. But the first stage must be improved also, with a better effectiveness of primary healthcare to reduce MLLA rates.

The main limitations of this study include our data. First, we used the national DATASUS database; therefore, it is not possible to know whether a patient who has undergone lower limb amputation has undergone previous diagnostic or surgical procedures. However, DATASUS is the largest national dataset with nearly a $70 \%$ penetrance and therefore is the best data available to evaluate the health system performance. Second, as this was a retrospective analysis, we don't have access to personal treatment plans, and as such, we do not know if MLLA patients had previous surgery or diagnostics. Patients under 40 years old and those who underwent MLLA due to trauma and oncological reasons were excluded in an attempt to decrease bias since patients under 40 years old are rarely affected by PAD, and MLLA is usually related to other causes. ${ }^{35}{ }^{36}$ While it is the best we can do, this choice could underrepresent the association of MLLA with septic patients who die without an amputation surgery. Another limitation concerns the fact that procedures performed by the private healthcare network were not accounted for, which would have resulted in even higher MLLA rates. Finally, because public healthcare in Brazil is universal, many patients may have originated from other states within the federation, and many patients from small municipalities may have travelled to larger cities within the state for treatment, introducing bias on the spatial distribution of the results. To mitigate this, we used the municipality of residence of each patient. Considering the high number of procedures analysed in the present study, external influences tended to be minimised without significantly compromising the findings.

\section{CONCLUSIONS}

The present study demonstrated that elevated lower limb amputation rates are concentrated in some regions of the state. Colour Doppler ultrasound is negatively associated with MLLA rates, while limb revascularisation surgery and illiteracy showed a positive association. Thus, taking into consideration the results, we can conclude that we should give more attention to the capacity of the municipalities to offer diagnostic tests or increase the infrastructure to improve access to population in order to reduce the need for invasive treatment.

Contributors RdLF: Substantial contributions to the conception or design of the work; or the acquisition, analysis or interpretation of data for the work; drafting the work or revising it critically for important intellectual content; final approval of the version to be published; agreement to be accountable for all aspects of the work in ensuring that questions related to the accuracy or integrity of any part of the work are appropriately investigated and resolved. PHI: Acquisition, analysis or interpretation of data for the work; final approval of the version to be published. ACD: Acquisition, analysis or interpretation of data for the work; drafting the work or revising it critically for important intellectual content; final approval of the version to be published. SQB: Drafting the work or revising it critically for important intellectual content; final approval of the version to be published. JV: Drafting the work or revising it critically for important intellectual content; final approval of the version to be published. CS: Drafting the work or revising it critically for important intellectual content; final approval of the version to be published. LA: Substantial contributions to the conception or design of the work; or the acquisition, analysis or interpretation of data for the work; drafting the work or revising it critically for important intellectual content; final approval of the version to be published; agreement to be accountable for all aspects of the work in ensuring that questions related to the accuracy or integrity of any part of the work are appropriately investigated and resolved.

Funding The authors have not declared a specific grant for this research from any funding agency in the public, commercial or not-for-profit sectors.

Map disclaimer The depiction of boundaries on this map does not imply the expression of any opinion whatsoever on the part of BMJ (or any member of its group) concerning the legal status of any country, territory, jurisdiction or area or of its authorities. This map is provided without any warranty of any kind, either express or implied.

\section{Competing interests None declared.}

Patient and public involvement Patients and/or the public were not involved in the design, or conduct, or reporting, or dissemination plans of this research.

Patient consent for publication Not required.

Provenance and peer review Not commissioned; externally peer reviewed.

Data availability statement Data are available in a public, open access repository. All information used in this work are third-party data. Those interested can access the data in the same manner as the authors and the authors did not have any special access privileges.

Open access This is an open access article distributed in accordance with the Creative Commons Attribution Non Commercial (CC BY-NC 4.0) license, which permits others to distribute, remix, adapt, build upon this work non-commercially, and license their derivative works on different terms, provided the original work is properly cited, appropriate credit is given, any changes made indicated, and the use is non-commercial. See: http://creativecommons.org/licenses/by-nc/4.0/.

\section{ORCID iD}

Rogério do Lago Franco http://orcid.org/0000-0002-5926-6941

\section{REFERENCES}

1 Rutherford RB, Baker JD, Ernst C, et al. Recommended standards for reports dealing with lower extremity ischemia: revised version. $J$ Vasc Surg 1997;26:517-38.

2 Campbell WB, Ridler BM, Szymanska TH. Current management of acute leg ischaemia: results of an audit by the vascular surgical society of great britain and ireland. Br J Surg 1998;85:1498-503.

3 Karapolat S, Dag O, Abanoz M, et al. Arterial embolectomy: a retrospective evaluation of 730 cases over 20 years. Surg Today 2006;36:416-9.

4 Duff S, Mafilios MS, Bhounsule P, et al. The burden of critical limb ischemia: a review of recent literature. Vasc Health Risk Manag 2019;15:187-208.

5 Jesus-Silva SGde, Oliveira JPde, Brianezi MHC, et al. Análise dos fatores de risco relacionados $\mathrm{s}$ amputações maiores e menores de membros inferiores em Hospital terciário. J Vasc Bras 2017;16:16-22.

6 Aboyans V, Sevestre M-A, Désormais I, et al. [Epidemiology of lower extremity artery disease]. Presse Med 2018;47:38-46.

7 Goodney PP, Travis LL, Nallamothu BK, et al. Variation in the use of lower extremity vascular procedures for critical limb ischemia. Circ Cardiovasc Qual Outcomes 2012;5:94-102.

8 Stevens CD, Schriger DL, Raffetto B, et al. Geographic clustering of diabetic lower-extremity amputations in low-income regions of California. Health Aff 2014;33:1383-90.

9 Dillon MP, Fortington LV, Akram M, et al. Geographic variation of the incidence rate of lower limb amputation in Australia from 2007-12. PLoS One 2017;12:e0170705.

10 Jones WS, Patel MR, Dai D, et al. Temporal trends and geographic variation of lower-extremity amputation in patients with peripheral artery disease: results from U.S. Medicare 2000-2008. J Am Coll Cardiol 2012;60:2230-6.

11 Margolis DJ, Hoffstad O, Nafash J, et al. Location, location, location: geographic clustering of lower-extremity amputation among Medicare beneficiaries with diabetes. Diabetes Care 2011;34:2363-7. 
12 Wrobel JS, Mayfield JA, Reiber GE. Geographic variation of lowerextremity major amputation in individuals with and without diabetes in the Medicare population. Diabetes Care 2001;24:860-4.

13 de Andrade L, Zanini V, Batilana AP, et al. Regional disparities in mortality after ischemic heart disease in a Brazilian state from 2006 to 2010. PLoS One 2013;8:e59363.

14 Rocha-Brischiliari SC, Andrade L, Nihei OK, et al. Spatial distribution of breast cancer mortality: socioeconomic disparities and access to treatment in the state of Parana, Brazil. PLoS One 2018;13:e0205253.

15 von Elm E, Altman DG, Egger M, et al. The strengthening the reporting of observational studies in epidemiology (STROBE) statement: guidelines for reporting observational studies. J Clin Epidemiol 2008;61:344-9.

16 IBGE. Instituto Brasileiro de Geografia E Estatística, 2018. Available: https://ibge.gov.br [Accessed 5 May 2018].

17 PNUD - Programa das Nações Unidas para o Desenvolvimento. Ranking IDHM Municípios 2010, 2014. Available: http://www.br.undp. org/content/brazil/pt/home/idh0/rankings/idhm-municipios-2010. html [Accessed 6 Oct 2018].

18 Ministério Da Saúde Do Brasil. Departamento de informática do Sistema Único de Saúde (DATASUS), 2018. Available: http://tabnet. datasus.gov.br [Accessed 5 May 2018]

19 Instituto De Terras. Cartografia E Geologia Do Paraná - ITCG, 2018. Available: http://www.itcg.pr.gov.br [Accessed 5 May 2018].

20 Anselin L. Interactive techniques and exploratory spatial analysis. In: Longley PA, Goodchild MF, Maguire DJ, et al, eds. Geographical information systems: principles, techniques, management and applications. New York: Wiley, 1998: 253-65.

21 Anselin L, Syabri I, Kho Y. GeoDa: an introduction to spatial data analysis. Geogr Anal 2006;38:5-22.

22 Lesage JP. Spatial Econometrics, 1998. Available: http://www. spatial- econometrics.com/html/wbook.pdf [Accessed 3 Aug 2019].

23 QGIS Development Team. QGIS geographic information system. open source Geospatial Foundation project, 2017. Available: http:// qgis.osgeo.org [Accessed 23 Oct 2017].

24 RStudio Team. RStudio: integrated development for R, 2019. Available: http://www.rstudio.com/

25 Peixoto AM, Zimpel SA, Oliveira ACAde, et al. Prevalência de amputações de membros superiores e inferiores no estado de
Alagoas atendidos pelo SUS entre 2008 e 2015. Fisioter. Pesqui. 2017;24:378-84.

26 Venermo M, Manderbacka K, Ikonen T, et al. Amputations and socioeconomic position among persons with diabetes mellitus, a population-based register study. BMJ Open 2013;3. doi:10.1136/ bmjopen-2012-002395. [Epub ahead of print: 0804 2013].

27 Hawkins RB, Charles EJ, Mehaffey JH, et al. Socioeconomic distressed communities index associated with worse limb-related outcomes after infrainguinal bypass. J Vasc Surg 2019;70:786-94.

28 Mestre XM, Castellote MAC, Coll RV, et al. Arterial mapping with duplex ultrasound: diagnostic-therapeutic strategy in patients with critical lower-limb ischemia. Int Angiol 2009;28:209-14.

29 Norgren L, Hiatt WR, Dormandy JA, et al. Inter-Society consensus for the management of peripheral arterial disease (TASC II). Eur J VasC Endovasc Surg 2007;33 Suppl 1:S1-75.

30 Sigl M, Noe T, Ruemenapf G, et al. Outcomes of severe limb ischemia with tissue loss and impact of revascularization in haemodialysis patients with wound, ischemia, and foot infection (WIfl) stage 3 or 4. Vasa 2020;49:63-71.

31 Ochoa Chaar Cl, Gholitabar N, Goodney P, et al. One-Year readmission after open and endovascular revascularization for critical limb ischemia. Ann Vasc Surg 2019;61:25-32.

32 Tunis SR, Bass EB, Steinberg EP. The use of angioplasty, bypass surgery, and amputation in the management of peripheral vascular disease. N Engl J Med Overseas Ed 1991;325:556-62.

33 Lin JH, Brunson A, Romano PS, et al. Endovascular-First treatment is associated with improved Amputation-Free survival in patients with critical limb ischemia. Circ Cardiovasc Qual Outcomes 2019;12:e005273.

34 Fowkes FG, Forster RB, Levin CE, et al. Prioritization of treatments for lower extremity peripheral artery disease in low- and middleincome countries. Int Angiol 2017;36:203-15.

35 Axley JC, McFarland GE, Novak Z, et al. Factors associated with amputation after peripheral vascular intervention for intermittent claudication. Ann Vasc Surg 2020;62:133-41.

36 Kannel WB, McGee DL. Update on some epidemiologic features of intermittent claudication: the Framingham study. J Am Geriatr Soc 1985;33:13-18 